\title{
Doğu Akdeniz Bölgesinde Bulunan Sulak Alanlarda Oluşan Toprakların Kil Minerali Özellikleri
}

\author{
Ahu Alev ABACI BAYAN ${ }^{1} \quad$ Kadir YILMAZ \\ ${ }^{1}$ Ahi Evran Üniversitesi Ziraat Fakültesi Toprak Bilimi ve Bitki Besleme Bölümü, Kırşehir \\ ${ }^{2}$ KSÜ Ziraat Fakültesi Toprak Bilimi ve Bitki Besleme Bölümü, Kahramanmaraş \\ $\bowtie: k y i l m a z @$ ksu.edu.tr
}

Geliș (Received): 27.01.2017

Kabul (Accepted): 22.02.2017

\begin{abstract}
ÖZET: Doğu Akdeniz Bölgesindeki Amik, Gavur ve Gölbaşı Gölleri sulak alan toprakları araştırma alanı olarak seçilmiştir. Toprakların kil minerali içeriklerini ve dağılımlarını belirlemek amacıyla çarpım faktörü yöntemi ile kantitatif kil analizi yapılmıştır. Kil mineralojisi analizinde baskın mineral tipi smektit olarak bulunmuş, bunu bulunma yüzdelerine göre paligorskit, illit, vermikulit ve kaolinit mineralleri takip etmiştir. Topraktaki yüksek kalsiyum düzeyi ve toprak pH' sının bazik olması smektitin baskın mineral olması uygun koşulları sağlamaktadır. Paligorskit mineralinin tüm topraklarda bulunması, bazik karakterli göl tabanlarında kalsiyum ve magnezyumun zengin olması, bu mineralin kararlılığını devam ettirmesi için uygun koşullar olduğunu göstermiştir. Ova toprakları arasında kil minerali tipleri arasında istatistiki bir farklılığın bulunmaması, kil minerali oluşum koşullarını sağlayan temel faktörlerin bütün ova topraklarında benzer özellikte olmasından kaynaklandığı, ovalar arasındaki başta amenajman olmak üzere kurutma çalışmalarının farklı zamanlarda olması ve bunlara bağlı olarak oluşan bazı fiziksel ve kimyasal farklılıkların, kil mineralleri oluşumları üzerine çok fazla etkili olmadığını göstermiştir.
\end{abstract}

Anahtar Kelimeler: Sulak alan, göl tabanı, toprak, kil minerali

\section{Clay Mineral Properties of the Soils of the Wetlands in the Eastern Mediterranean Region}

ABSTRACT: Amik, Gavur and Golbasi Lakes wetland soils's in the East Mediterranean Region were selected as the research area. Quantitative clay analysis was performed by means of factorial method to determine clay mineral contents and distributions of soils. Clay mineralogy analysis was domination of smectite mineral soils, and was followed by palygorskite, illite, vermiculite and kaolinite, respectively. The higher calcium level in the soil and the basicity of the soil $\mathrm{pH}$ make smectite the predominant mineral, thus providing favorable conditions. The presence of palygorskite mineral in all soils indicates that the richness of calcium and magnesium in the basement lake basins is a favorable condition for this mineral to maintain its stability. Having no statistical differences found among clay mineral types in the plain soil was due to presence of similar factors for clay mineral formation conditions in all soils in the plain and the different timing of drying practises, consequently, occuring some physical and chemical differences did not affect much on clay minerals formation.

Keywords: Wetland, lake floor, soil, clay mineral

\section{GíRiş}

Sulak alanlar sahip oldukları biyolojik çeşitlilik ve biyomas üreten ekosistemler arasında bulunmaktadır. Ülkenin olduğu kadar dünyanın da doğal zenginlikleri arasında yer alan doğal işlevleri ve ekonomik özellikleri ile yeryüzünün en önemli ekosistemleridir. Sulak alanların kurutulmaya başlaması ile birlikte ekolojik dengenin bozulduğu ve bu alanlarda ötrifikasyon olayı meydana gelerek, suyun fiziko-kimyasal özelliklerinin değişmesi ve oksijen miktarının azalması ile birçok canlının yaşamının tehlikeye düştüğü (Cirik, 1993), kurutma sonucu jipsli minerallerin kapilarite ile yüzeye kadar yükselerek, tuz konsantrasyonunu arttırdığı (Zor ve Şengün, 2002), bunun sonucunda tuzluluk ve alkaliliğin toprak profilindeki etkin tuz kökleri olan Cl- ve SO4- ile Na miktarında artışın olduğu, tarımsal kullanıma açılan toprakların kimyasal özelliklerinde önemli değişikliklerin olduğu gözlenmiştir (Sarı ve ark., 2000).

Göller Bölgesinde yapılan bir araştırmada, kil fraksiyonunda smektit, illit, kaolinit ve kuvars mineralleri bulunmuş, piklerin çok belirgin olmaması özellikle illit ve kaolinitin zayıf kristalli olduğu, smektitin daha iyi kristalize olduğu şeklinde değerlendirilmiştir (Şenol ve Akgül, 2013). Kahramanmaraş'taki Aridisol, İnceptisol, Histosol, Vertisol ve Mollisol ordolarında, çarpım faktörü yöntemi ile kantitatif kil analizi yapılmış, baskın kil minerali smektit olarak belirlenmiş, bunu illit, kaolinit, paligorskit ve vermikülit takip etmişstir. Smektitin baskın mineral olarak bulunması, daha önce kurak ve yarı kurak bölgelerdeki topraklar üzerinde yapılan araştırma bulguları ile uyumlu olduğu ve paligorskitin kireçli materyaller içerisinde kararlılığını devam ettirdiği belirtilmiştir (Yılmaz, 2001). Harran Ovası'nda çarpım faktörü yöntemi ile kantitatif kil analizi sonucunda, baskın kil mineralinin smektit olduğu, bunu illit, kaolinit, paligorskit ve vermikülitin izlediği saptanmıştır (Yılmaz, 1990). Ganj deltasındaki sulak alan topraklarındaki çalışmada, baskın minarelerinin sırasıyla smektit, kaolinit, klorit ve mikanın olduğu belirtilmiştir (Hussain ve ark., 2006). Ayrıca Yılmaz ve Akça (2000)' nın Kahramanmaraş Ovası topraklarında, Gürel (1992)' in Ceylanpınar Ovası topraklarında yaptıkları araştırmalarda, baskın kil minerali olarak smektiti tespit etmişlerdir. Hseung ve Jackson (1952), Çin'de bulunan 18 adet büyük toprak gruplarını incelemişler, çeşitli 
parçalanma ayrışma derecesine bağlı olarak çöl topraklarından latosollere kadar farklı fraksiyonlarda Xray çekimleri ve element analizleri yapmışlar ve araştırma sonucunda kil minerali dağılımının toprakların oluşum koşullarlına bağlı olarak farklılıklar gösterdiğini tespit etmişlerdir. Serpantin, kireçtaşı ve bazalt ana materyalleri üzerinde oluşan toprakların kil oranları ile strüktür stabilitesi arasındaki ilişkilerin incelendiği bir araştırmada da, sığ toprakların en düşük strüktür stabilitesine, en yüksek smektit/kaolinit oranına ve en düşük $\mathrm{Ca}+2 / \mathrm{Mg}+2$ oranına, orta derinlikteki toprakların en yüksek $\mathrm{Ca}+2 / \mathrm{Mg}+2$ oranına ve derin toprakların ise en yüksek strüktür stabilitesine ve en düşük smektit/kaolinit oranıyla birlikte en yüksek Al-Fe oksit içeriğine sahip oldukları tespit edilmiştir. Sı̆g ve orta derinlikteki topraklarda baskın kil minerali tipinin smektit, derin topraklarda ise baskın kil minerali tipinin kaolinit olduğu bulunmuştur (Y1lmaz ve ark., 2005). Şenol ve ark. (2014) tarafından kil tiplerini belirlemeye yönelik yapılan bir çalışmada, güney yamaçta yoğun smektit ve smektit-illit ara tabakalı kil mineralleri söz konusu iken, kuzey yamaç kesimlerinde bolluk sırasına göre illit, kaolinit ve smektitin varlığını tespit etmişlerdir.

Yukarıda verilen literatür araştırmalarından da görüleceği gibi Ülkemizde ve Dünya da toprakların kil mineralleri içeriğinin belirlenmesine yönelik birçok çalışma yapılmasına karşın sulak alanlar üzerinde oluşan toprakların kil mineralojisi üzerine yapılan çalışmalar yok denecek kadar azdır. Bu çalışma ile Türkiye'nin Doğu Akdeniz Bölgesinin en önemli sulak alanları arasında bulunan Amik, Gavur ve Gölbaşı Gölleri topraklarının kil minerali tipleri ve bunların oluşum koşulları ile olan ilişkileri araştırılmıştır.

\section{MATERYAL ve METOT \\ Materyal}

Amik Gölü, Antakya-Kahramanmaraş grabeninin en güneyini oluşturan Amik Ovası'nın tabanında bulunmaktadir. Ova deniz seviyesinden ortalama $83 \mathrm{~m}$ yükseklikte yer almaktadır. Ovanın toplam alanı yaklaşık 65000 ha' dır. Kuaterner yaşlı alüvyal dolgudan oluşan Amik Gölü çevresinde geniş serpantinlerde geniş yer kaplamaktadır (Küçük, 2002). Gavur Gölü, AntakyaKahramanmaraş grabeninde ve deniz seviyesinden ortalama $478 \mathrm{~m}$ yükseklikte yer almaktadır. Bu sulak alan, güneyindeki Sağlık Ovası'nın en çukur alanında bulunmaktadır. Doğal durumunda kapladığı alan 7125 ha'dır. Pre Alpin, Alpin ve Post Alpin formasyon şeklinde gruplandırılan Gavur Gölü havzanın temeli metamorfik ve metamorfik olmayan çeşitli kuvarsit, kumtaşı, silttaşı ve şeyller oluşturmakta ve alanda serpanitler ile birlikte diğer ultrabazikler yaygın olarak bulunmaktadır (Gürbüz ve ark., 2003). Gölbașı Gölleri Doğu Anadolu Fay Zonu içerisinde Gölbaşı Depresyonunda yer almakta, Kuzeydoğu ve Güneybatı yönündeki çöküntü hendeğinin deniz seviyesine göre ortalama yükseltisi 885 m'dir. Toplam 1687 hektarlık bir alanı kaplamaktadır. Karstik-tektonik kökenli olan Gölbaşı Gölü, kuzeydoğu-güneybatı istikametinde bir çöküntü hendeği içinde yer almakta olup, Doğu Anadolu Fay Zonu üzerindedir (Akdemir, 2004). Toprak örnekleri Amik, Gavur ve Gölbaşı Gölleri’nin göl aynasından enine kesit alarak açılan toprak profillerinden horizon esasına göre alınmış ve GPS yardımı ile koordinatları belirlenmiş, Şekil 1'de araştırma alanları verilmiştir.

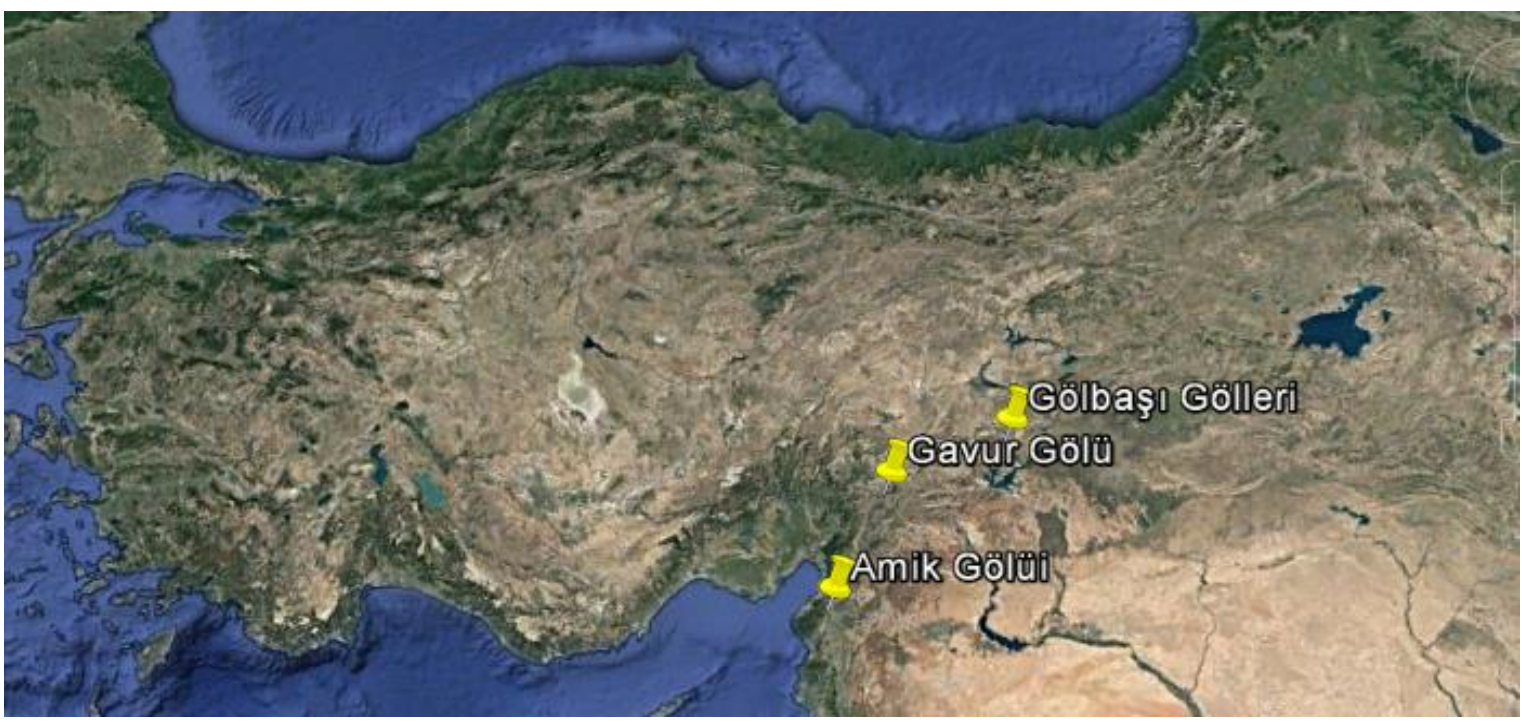

Şekil 1. Amik Gölü, Gavur Gölü ve Gölbaşı Gölleri sulak alanı

\section{Metot}

Araştırma alanlarında toplam 26 toprak profil açılmış, Jackson (1962) tarafından bildirilen ilkeler doğrultusunda alınan toprak örnekleri laboratuvar ortamında kurutulup, $2 \mathrm{~mm}$ ' lik elekten geçirilmiştir.
Toprak reaksiyonu Thomas (1996)'a, elektriki iletkenlik Tüzüner (1990)'e, toplam kireç Gülçur (1974)'a, değişebilir Mg tayini Helmke ve Sparks (1996)'a ve toplam kimyasal analizler Yılmaz (1990)' in belirttiği HF fusyonuna göre yapılmıştır. Kil mineralojisi analizi için; 
karbonatların tahribi ve +2 değerlikli katyonlar pH' s1 5 olan sodyum asetat-asetik asit tampon çözeltisiyle, organik madde hidrojen peroksitle, serbest demir oksitler sitrat-dithionit-bikarbonat çözeltisi ile ortamdan uzaklaştırılmıştır. Kum ıslak elemeyle, silt ise Stokes yasasından yararlanılarak kil fraksiyonundan ayrılmıştır (Jackson, 1969). Kil örneklerinin magnezyum ve potasyum iyonları ile doyurulmasindan sonra slaytlar hazırlanarak X-ışını kırınımları çekilmiş ve kırınımların doruk alanları hesaplanarak minerallerin X-1şını kırınım güçleri belirlenmiştir. Kantitatif kil analizinde, Yılmaz ve Sayın (1998)' in Çukurova Bölgesi toprakları ve Yılmaz (1990)' in Harran Ovası topraklarında elde ettiği çarpım faktörü katsayıları kullanılarak kil mineral tipleri oransal olarak kantitatif olarak hesaplanmıştır. Araştırıcılar incelenen topraktan smektit, paligorskit ve illiti saf olarak izole etmiş, izole edilen bu kil minerallerden 1:1 oranında karışımlar hazırlayarak minerallerin X-1şınını difrakte etme güçlerini tayin etmişlerdir. Kaolinit çarpım faktörünü dahili standart yöntemi ile belirlemişlerdir. Kullanılan çarpım faktörü katsayıları, smektit/illit: 2.25, smektit/paligorskit: 3.37, smektit/kaolinit: 3.29' dur. Kil minerallerinin doruk alanının ölçümü ile bulunan $\mathrm{X}$ ışınını difrakte etme güçleri, çarpım faktörü katsayıları kullanılarak smektite göre normalize edilmiştir.
Analizler sonucu elde edilen bulgular, SPSS programı (IBM SPSS Advanced Statistics version 19.0.0) kullanılarak varyans analizi yapılmıştır. Hem alan topraklarında hem de göl aynası içerisinde bulunan topraklarda yapılan varyans analizi sonucunda, önemli bulunan gruplar arasındaki farklılık Duncan çoklu karşılaştırma testi ile incelenmiştir.

\section{BULGULAR ve TARTIŞMA}

Üç farklı alanda yapılan kantitatif kil minerali difraktogramları Şekil 2 ve analiz sonuçları Çizelge 1' de verilmiştir. Çizelge 1 incelendiğinde, Amik, Gavur ve Gölbaşı Gölleri topraklarında smektit grubu mineraller baskın mineral tipi olarak gözlenmiştir. Yüksek kalsiyum düzeyi ve $\mathrm{pH}$ ' nın bazik olması smektitin baskın mineral olarak oluşması için uygun koşulları sağlamaktadır. Yılmaz (1990) tarafindan Harran Ovası' nda 25 toprak serisinde ve Yılmaz (2001) tarafından Kahramanmaraş' ta yer alan toprak ordoları üzerinde yapılan çalışmalarda da baskın kil mineral tipi smektit olarak tespit edilmiştir. Daha önce kurak ve yarı kurak bölge topraklarında yapılan araştırmalarda da baskın kil tipinin smektit olduğu bulunmuştur (Ergene, 1963; İnce, 1984; Hocaoğlu, 1970; Güzel ve Wilson, 1985).

Çizelge 1. Amik Gölü, Gavur Gölü ve Gölbaşı Gölleri topraklarının kil fraksiyonunun mineralojik analiz sonuçları

\begin{tabular}{clccccc}
\hline \multirow{2}{*}{ Bölgeler } & & Smektit & Vermikulit & Paligorskit & İllit & Kaolinit \\
\cline { 3 - 7 } & & & & & & \\
\hline \multirow{2}{*}{ Amik Gölü } & En düşük & 35.2 & 14.3 & 4.1 & 3.1 & 2.9 \\
& En yüksek & 75.6 & 39.4 & 16.5 & 16.4 & 11.7 \\
& Ortalama & 50.8 & 23.7 & 10.0 & 8.2 & 7.3 \\
Gavur Gölü & En düşük & 9.0 & 7.9 & 6.0 & 5.3 & 4.1 \\
& En yüksek & 65.7 & 59.8 & 19.9 & 19.6 & 14.3 \\
& Ortalama & 43.3 & 22.7 & 12.8 & 12.7 & 8.4 \\
Gölbaş1 Gölü & En düşük & 9.9 & 2.4 & 6.5 & 6.2 & 4.8 \\
& En yüksek & 79.1 & 57.3 & 17.1 & 20.4 & 15.6 \\
& Ortalama & 51.1 & 18.1 & 11.1 & 10.4 & 9.2 \\
\hline
\end{tabular}




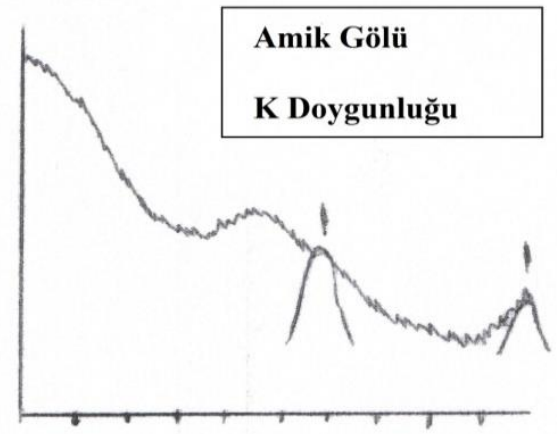

$2 \boldsymbol{\theta}$

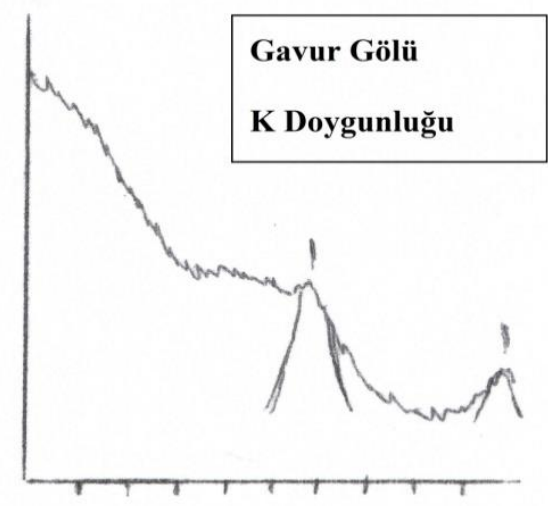

$2 \theta$

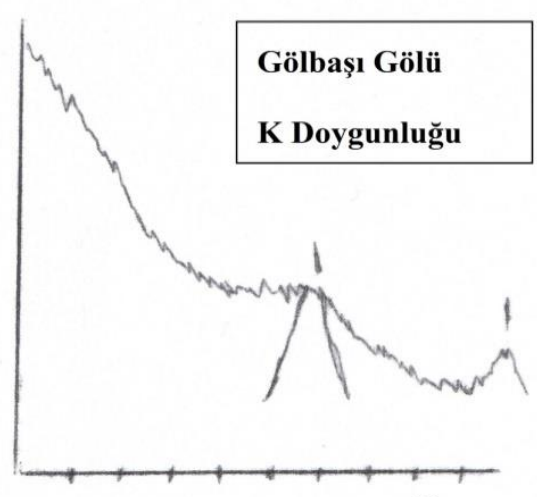

$2 \theta$
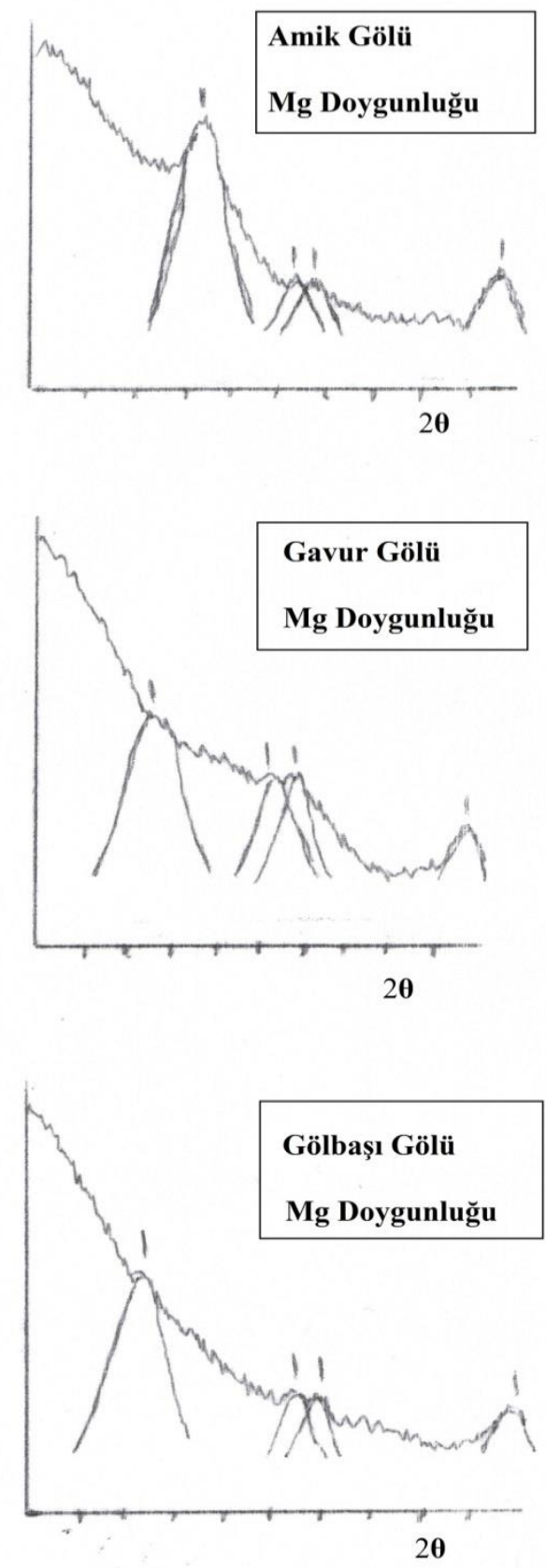

Şekil 2. Kantitatif vermikülit analizinde $\mathrm{K}$ ve $\mathrm{Mg}$ doygunluğunda meydana gelen değişiklikleri gösteren X-1şını difraktogramları

Topraklarda yapılan kimyasal ve toplam element analizi sonuçları Çizelge 2'de verilmiştir. Çizelge 2 incelendiğinde toprakların $\mathrm{pH}$ değerleri genellikle bazik özellikte olup çoğunlukla 7' nin üzerindedir. Değişsebilir tabiattaki katyonlar içerisinde kalsiyum ve magnezyum baskın düzeydedir. Bu katyonların değişebilir katyonlar içerisindeki oranı bütün araştırma alanı topraklarda \% 80'in üzerindedir. $\mathrm{SiO} 2$ düzeyinin (\% 62.49-66.46) diğer elementlerden fazla oranda bulunduğu gözlenmiştir. İkinci sırada $\mathrm{CaO}$ (\% 14.26-18.01) yer almış bunu 
KSÜ Doğa Bil. Derg., 20(4), 385-392, 2017

KSU J. Nat. Sci., 20(4), 385-392, 2017
Arastırma Makalesi/ Research Article DOI : 10.18016/ksudobil.288277 sirasiyla Al2O3 (\% 6.01-6.79), Fe2O3 (\% 2.81-5.30), $\mathrm{MgO}(\%$ 1.38-2.19), Na2O (\% 2.20-2.60) ve K2O (\% 1.43-2.22) takip etmiştir. Şenol ve Akgül (2013) tarafından Göller Bölgesinde yapılan bir araştırmada da benzer bulgular görülmüştür. Üç sulak alanda yapılan kimyasal analiz sonuçlarında, $\mathrm{Al} 2 \mathrm{O} 3$ ve $\mathrm{SiO} 2$ çözünemez ve dirençli oksitlerin yüksek oranlarda bulunması beklenen bir sonuç olup, majör elementlerden $\mathrm{CaO}, \mathrm{MgO}$ ve $\mathrm{Na} 2 \mathrm{O}$ gibi elementler çözünebilir ve mobil elementler (Mackereth, 1966; Engstrom ve Wright, 1984) olmasına karşın, toprak profilinde yüksek düzeylerde bulunmuştur. Kalsiyumun bölgede yaygın olarak bulunan kireç taşı ile magnezyumun ise yine yaygın olarak bulunan serpantin ile ilişkili olduğu görülmüş ve bu elementlerin konsantrasyonun yüksekliği alanlardan gelen yüzey akış sularının bir ürünü olarak değerlendirilmiştir.

Çizelge 2. Toprakların bazı kimyasal özellikleri

\begin{tabular}{|c|c|c|c|c|c|c|c|c|c|c|c|c|}
\hline \multirow[b]{2}{*}{ Bölgeler } & & \multirow[b]{2}{*}{$\mathrm{pH}$} & \multirow[b]{2}{*}{$\begin{array}{l}\text { Top } \\
\text { tuz. }\end{array}$} & \multirow[b]{2}{*}{$\begin{array}{c}\text { Top. } \\
\mathrm{CaCO}_{3}\end{array}$} & \multirow[b]{2}{*}{ Değ. Mg } & \multicolumn{7}{|c|}{ Toplam elementler } \\
\hline & & & & & & $\mathrm{SiO}_{2}$ & $\mathrm{CaO}$ & $\mathrm{Al}_{2} \mathrm{O}_{3}$ & $\mathrm{Fe}_{2} \mathrm{O}_{3}$ & $\mathrm{MgO}$ & $\mathrm{Na}_{2} \mathrm{O}$ & $\mathrm{K}_{2} \mathrm{O}$ \\
\hline & & & $\%$ & $\%$ & $\begin{array}{c}\mathrm{cmol}_{\mathrm{c}} \\
\mathrm{kg}^{-1}\end{array}$ & & & & $\%$ & & & \\
\hline \multirow[t]{3}{*}{ Amik Gölü } & Min. & 7.91 & 0.02 & 7.52 & 9.38 & 50.38 & 11.23 & 3.35 & 3.54 & 0.92 & 0.69 & 0.96 \\
\hline & Max. & 8.45 & 2.27 & 62.07 & 18.49 & 72.40 & 28.29 & 9.50 & 6.94 & 3.82 & 3.10 & 2.62 \\
\hline & Ort. & 8.24 & 0.56 & 27.52 & 14.45 & 62.49 & 18.01 & 6.01 & 5.30 & 2.19 & 2.20 & 1.86 \\
\hline \multirow[t]{3}{*}{ Gavur Gölü } & Min. & 7.46 & 0.05 & 1.13 & 2.99 & 47.59 & 9.78 & 4.67 & 1.35 & 0.42 & 1.77 & 0.87 \\
\hline & Max. & 8.22 & 1.09 & 49.40 & 17.95 & 74.76 & 28.84 & 9.80 & 4.61 & 3.19 & 3.22 & 2.59 \\
\hline & Ort. & 7.81 & 0.36 & 19.71 & 8.57 & 66.22 & 16.08 & 6.79 & 2.81 & 1.86 & 2.60 & 1.43 \\
\hline \multirow[t]{3}{*}{ Gölbaşı Gölü } & Min. & 6.51 & 0.04 & 0.79 & 0.98 & 52.60 & 9.65 & 3.38 & 2.03 & 0.35 & 1.25 & 0.96 \\
\hline & Max. & 8.09 & 0.96 & 61.26 & 18.02 & 75.83 & 28.91 & 9.87 & 7.77 & 3.19 & 3.30 & 4.22 \\
\hline & Ort. & 7.78 & 0.12 & 19.81 & 9.44 & 66.46 & 14.26 & 6.54 & 4.57 & 1.38 & 2.52 & 2.22 \\
\hline
\end{tabular}

Amik, Gavur ve Gölbaşı Gölleri araștırma alanı topraklarında yapılan istatistiki analiz sonucunda, smektit kil minerali tipi ile illit ve kaolinit kil tipi arasında önemli negatif ilişki ( $\% 1, \%$ 1) bulunmuştur. Benzer bulguya Charles ve ark. (2010) tarafindan, Nijerya'nın Güneydoğusundaki büyük toprak gruplarının kil mineralojisi incelemelerinde ve Şenol (2012) tarafindan Göller Bölgesinde rastlanmış, kaolinitin baskın olduğu alanlarda smektit kil tipinin daha az oranda bulunduğu bildirilmiştir. Benzer bulgular Yurdakul (2009), Seyrek ve ark. (2005), Korkmaz (2005), Udeigwe (2001), Igwe ve ark. (1999), Kapur ve ark. (1991), Stern ve ark. (1991), Yilmaz (1990) ve Sayın (1983) tarafindan yapılan araştırmalarda da gözlenmiştir.

Paligorskit kil tipi ile smektit kil tipi arasında önemli negatif ilişki (\% 1) ve değişebilir magnezyum, arasında önemli pozitif ilișki olduğu $\left(\begin{array}{llll}\% & 5, & 0.1,\end{array}\right)$ tespit edilmiştir. Topraklarda baskın durumda olan smektitin oransal olarak azalmasına bağlı olarak, yine topraklarda orta düzeylerde bulunan paligorskitin artış göstermesi bu minerallerin oluşum koşullarıyla ilişkili olabileceği düşünülmüştür. Smektit tabaka yapılı bir mineral olup, genellikle bazik koşullarda kalsiyumca zengin topraklarda kararlılığını sürdüren bir mineraldir (Yılmaz, 1999). Paligorskit ise tüp şeklinde ve zincir yapısında olan eski göl tabanlarında ve magnezyumca zengin topraklarda oluşumu beklenen bir mineraldir (Y1lmaz, 1999). Araştırma alanlarında kalsiyumca zengin olan kireçtaşı ve magnezyumca zengin olan serpantinin yaygın olarak bulunması, bu minerallerin oluşumu için uygun koşulları sağlamaktadır. Benzer bulguya, Yılmaz (1990) tarafindan yapılan Harran ovası topraklarının mineralojik karekterizasyonu çalışmasında da rastlanmıştır. İnceleme alanındaki 25 serinin 17 'sinde profil derinliği arttıkça paligorskit miktarı artmakta, smektit miktarı azalmaktadır. Harran ovasında paligorskit ile smektit arasında $\% 0.1$ düzeyinde negatif ilişki olduğu, bu iki mineralin birbirine dönüştüğü fikrini kuvvetlendirdiğini bildirilmiştir. $\mathrm{Bu}$ minerallerin birbirine dönüşmesi, ortamın şartlarına göre birinin kararlı olması ve diğerinin kararsız olması anlamına geldiğini ortaya koymaktadır. Ayrıca aynı araştırmacı, magnezyum ile paligorskit arasında $\%$ düzeyinde bulduğu pozitif ilişkiyi magnezyumun paligorskitten kaynaklandığına işaret ettiğini belirtmiştir. Bu bulgular Çakmaklı (2008), Seyrek ve ark. (2005) ve Aydemir (2001)'in yaptığı çalışmalarla da desteklenmiştir. Paligorskit, göl tabanı olan alanlarda yaygın olarak bulunmakta ve oluşumunda $\mathrm{Mg}$ elementi etken rol oynamaktadır (Y1lmaz, 1999). Paligorskitin yüksek oranda bulunduğu Vertisol ordosunda değișebilir $\mathrm{Mg}$ iyonunun fazla olduğunu ve Harran ovası topraklarında yapılan araştırmalardaki paligorskit kil minerali ile $\mathrm{Mg}$ iyonu arasındaki \% 0.1 düzeyindeki pozitif ilişkinin bulunduğu belirtilmektedir (Yılmaz, 1990, Y1lmaz ve ark., 1998, Kapur ve ark., 1990).. Çalışma alanımız olan üç araştırma alanı da çok uzun yıllardan bu yana göl sahası olan alanlardır. Sulu ve bazik 
KSÜ Doğa Bil. Derg., 20(4), 385-392, 2017

KSU J. Nat. Sci., 20(4), 385-392, 2017
Arastırma Makalesi/ Research Article

DOI : 10.18016/ksudobil.288277 koşullarda, özellikle magnezyumun bulunduğu ortamlarda bu mineralin oluşumu beklenmektedir. Amik, Gavur ve Gölbaşı Gölleri toprakları, paligorskitin oluşumuna uygun koşullardır. Araştırma alanı topraklarında bu mineralin görünmesi uygun koşulların varlığının bir sonucu olarak değerlenilmiştir.

Topraklarda yapılan korelasyon analizi sonucunda kaolinit kil tipi ile toplam kireç içeriği arasında önemli negatif (\% 5), ilişki tespit edilmiştir. Kaolinit, genellikle pH'nın 7'den düşük olduğu, bazik katyonlarca fakir, SiO2/R2O3 (R2O3: Fe2O3+Al2O3) oranının 2'den düşük olduğu koşullarda kararlılığını devam ettiren bir mineral olarak değerlendirilse de Türkiye' de bazik koşulların olduğu alanlarda da kaolinit kil mineraline rastlanmaktadır (Sayın, 1999). Kaolinitin oluşum koşulları ile uyumlu olan bu ilişkiye benzer bir sonuçta, Yeşilsoy ve Kapur (1982) tarafından Türkiye'de yarı yağışlı bir bölgede yer alan terrosalar üzerinde gelişen kireçsiz kahverengi toprak üzerine yaptıkları çalışmada elde edilmiştir. Altınbaş (1985), Kula ve yöresi bazaltik lav, kül ve cürufları üzerinde oluşan kireçsiz kahverengi topraklardaki kil minerallerinin kaolinit, illit, montmorillonit, vermiküllit, halloysit ile düzenli ara tabakalı ve karışık tabakalı mineraller olduğunu bildirmiştir. Mikaşist ana materyalleri üzerinde oluşan asidik kahverengi orman topraklarında ise, tüm profil ve horizonlarda kaolinit mineralinin başat olduğunu ve intensitesinin de toprak derinliğine paralel olarak arttığını, kaoliniti başatlık sırasına göre illit, montmorillonit ve vermiküllit izlediğini belirtmiştir.
Sayın (1983), Hatay-Reyhanlı'da yumuşak kireçtaşı üzerinde gelişen profilde illit ve kaolinit baskın bulunmuş, smektite rastlanmadığını rapor etmiştir. Yukarıda belirtilen araştırmacıların elde ettiği bulgular genellikle kireç içeriğinin düşük olduğu bazik koşullarda kaolinit oluşumunun düşük düzeylerde kalacağını göstermektedir.

Çalışma alanı topraklarının seçilmiş horizonlarındaki kil mineralleri dağılımı tek yönlü varyans analizi yapılarak, önemli bulunan gruplar arasındaki farklılık Duncan çoklu karşılaştırma testi ile araştırılmış ve bulgular Çizelge 3'de verilmiştir. Üç göl alanında yer alan toprakların kil tiplerinin oransal bulunma değerleri arasında istatistiki bir farklılığın olmaması, ovalarda kil minerallerinin oluşum koşullarının bir ölçütü olarak kabul edilen $\mathrm{pH}, \mathrm{SiO} 2$ 'in ve $\mathrm{Al} 2 \mathrm{O} 3+\mathrm{Fe} 2 \mathrm{O} 3$ değerlerinin benzer olması ve bu minerallerin oluşum koşulları ile uyumlu olmasından kaynaklandığı ve ovada bunlar arasındaki değişkenliklerin kil minerallerinin oluşum koşulları sınırlarının dışına çıkmadığı takdirde çok da etkili olmadığı sonucuna varılmıştır. Smektit ve paligorskit minarelerinin yanı sira ovada bulunan vermikulit, illit ve kaolinit mineralleri ülkemizin bugünkü ve geçmiş dönemlerdeki iklim ve toprak özeliklerine bağlı olarak gözlenen minerallerdir. Yapılan araştırmalarda Harran, Çukurova ve İç Anadolu bölgelerindeki topraklarda da bu minerallere rastlanılmaktadır (Yilmaz, 1990; Lavkor, 2006; Korkmaz, 2005).

Çizelge 3. Toprakların mineralojik özelliklerinin Duncan Testi sonuçları

\begin{tabular}{lccccc}
\hline Bölge & Smektit & Vermikülit & Paligorskit & Illit & Kaolinit \\
\hline Amik Gölü & $50.78 \pm 8.10$ & $23.69 \pm 7.12$ & $10.01 \pm 1.84$ & $8.15 \pm 1.98$ & $7.34 \pm 1.45$ \\
Gavur Gölü & $43.32 \pm 6.91$ & $22.73 \pm 6.50$ & $12.83 \pm 1.68$ & $12.71 \pm 1.81$ & $8.40 \pm 1.59$ \\
Gölbaş1 Gölleri & $51.12 \pm 8.15$ & $18.13 \pm 4.42$ & $11.09 \pm 1.14$ & $10.42 \pm 1.23$ & $9.21 \pm 0.98$ \\
\hline Önem düzeyi & $\mathrm{p}<0.727$ & $\mathrm{p}<0.742$ & $\mathrm{p}<0.521$ & $\mathrm{p}<0.258$ & $\mathrm{p}<0.603$ \\
\hline Aynı sütun içerisinde farklı sembol ile gösterilen ortalama değerler Duncan testine göre $\mathrm{p} \leq 0.05$ düzeyinde istatistiki olarak önemlidir. \\
\hline
\end{tabular}

Üç araştırma alanı topraklarının taban arazi pozisyonunda ve $\mathrm{pH}$ 'sının 7'nin üzerinde olması, smektit grubu kil mineralinin baskın olmasını sağlamıştır. Paligorskit mineralinin tüm topraklarda bulunması, bazik karakterli göl tabanlarında kalsiyum ve magnezyumun zengin olması, bu minerallerin kararlığını devam ettirmesi için uygun koşullar olduğunu göstermiştir. Göl tabanlarında smektitin baskın olması ve paligorskit mineralinin görülmesi bu minerallerin oluşum koşulları ile uyumlu olduğu sonucu çıkarılmıştır.

Sonuç olarak farklı dönemlerde kurutulmaya tabi tutulan ve üzerinde farklı tarımsal faaliyetler ve amenajman uygulamaları yürütülen üç göl alanı üzerinde yapılan kantitatif kil mineralleri analiz sonucunda; bu uygulamaların toprakların kil minerali dağılımında etkilemediği, uzun yıllar içerisinde değişime uğrayan kil mineral tipleri gibi bazı toprak özellikleri yönünden araştırma alanı toprakları arasında bir farklılığın olmadığı, ancak yapılan uygulamalara bağlı olarak toprakların organik madde içeriği, tuzluluk gibi bazı özellikleri yönünden önemli farklılığın oluştuğu görülmüştür (Abacı Bayan, 2016). 
KSÜ Doğa Bil. Derg., 20(4), 385-392, 2017

KSU J. Nat. Sci., 20(4), 385-392, 2017
Araștırma Makalesi/ Research Article

DOI : 10.18016/ksudobil.288277

\section{TEŞEKKÜR}

$\mathrm{Bu}$ çalışma Kahramanmaraş Üniversitesi Bilimsel Araştırma Projeleri Koordinasyon Birimi tarafindan desteklenen 2013/2-32 D nolu projenin bir bölümüdür.

\section{KAYNAKLAR}

Abacı Bayan AA 2016. Doğu Akdeniz Bölgesinde Yer Alan Sulak Alanlarda Oluşan Toprakların Özellikleri, Verimlilik Düzeyleri ve Sorunları. Kahramanmaraş Sütçü İmam Üniversitesi, Fen Bilimleri Enstitüsü, Toprak Bilimi ve Bitki Besleme Anabilim dalı, Doktora tezi. 120123 ss.

Altınbaş Ü 1985. Bazalt (Kula) ve Mikaşist (BozdağÖdemiş) Ana Özdekleri Üzerinde Oluşmuş Toprakların Kil Mineralleri Bileşimi. II. Ulusal Kil Sempozyumu Bildiriler. s: 273-289.

Akdemir İO 2004. Gölbaşı İlçesi' nin (Adıyaman) Beşeri ve İktisadi Coğrafyası, Frrat Üniversitesi, Sosyal Bilimler Enstitüsü, Coğrafya Anabilim Dalı, Doktora Tezi, Elazığ

Aydemir S 2001. Palygorskite-influenced vertisols and vertic like soils in the Harran Plain in the southeastern Turkey. $\mathrm{PhD}$. Thesis, Texas A\&M University, Soil and Crop Sciences Department, College Station, TX 77843, USA.

Charles A, Zarei M, Stahr K 2010. Fe and Al oxides distribution in some ultisols and inceptisols of southeastern Nigeria in relation to soil total phosphorus. Environ Earth Sci 60:1103-1111 DOI 10.1007/s12665009-0254-7

Cirik S 1993. Sulak Alanlar. Ege Üniversitesi. Su Ürünleri Fakültesi, İzmir.

Çakmaklı M 2008. Harran Ovası Topraklarının Kökeni Ve Oluşum Mekanizmaları (Jeoloji ve Toprak İlişkileri). Doktora Tezi. Harran Üniversitesi Fen Bilimleri Enstitüsü Toprak Anabilim Dalı, Şanlıurfa.

Engstrom DR, Wright HE 1984. Chemical Stratigraphy of Lake Sediments as A Record of Environmental Change. In: Haworth, E.Y. and Lund, J.W.G., (editors), Lake Sediments and Environmental History. Leicester University Press, 11-67.

Ergene A 1962. Fırat Nehri ile Amonos Dağları Arasındaki Bölgede Teşekkül Eden Kızıl Topraklar Üzerinde Bir Araştırma, A. Ü. Z. F. Yayınları No: 2.

Gülçur F 1974. Toprağın Fiziksel ve Kimyasal Analiz Metodları, İstanbul Üniversitesi Orman Fakültesi Yayınları, İ. Ü. Yayın No: 1970, O. F. Yayın No: 201, Kutulmuş Matbaası, İstanbul.

Gürbüz, M, Korkmaz H, Gündoğan R, Diğrak M 2003. Gavur Gölü Bataklığı. Coğrafi Özellikleri ve Rehabilitasyon Planı. T.C. Kahramanmaraş Valiliğii. İl Çevre Müdürlüğü Yayınları, No:1.

Gürel AN 1992, Ceylanpınar Ovasında Bazalt Akıntıları Üzerinde Oluşan Toprakların Genesisleri. Doktora Tezi. Çukurova Üniversitesi, Fen Bilimleri Enstitüsü Toprak Ana Bilim Dalı Adana.

Güzel N, Wilson MJ 1985. High-Magnesium Clays From Alluvial Soils of the Acipayam Plain Southern Turkey. P.117-123 In J. Konta (ed) Proc. 5 th Meet, European Clay Groups, Praque Charles Univ., Praque.

Helmke PA, Sparks DL 1996. Lithium, Sodium, Potassium, Rubidium, and Calcium, in Sparks, D.L., (Ed) Methods of Soil Analysis, Part 3, Chemical Methods, SSSA Book Series Number 5, SSSA., Madison,WI, P:551-574.

Hocaoğlu ÖL 1970. Diyarbakır, Erzurum ve Rize Bölgesinde Bazalt Kayalarından Oluşan Topraklardaki Kil Mineralleri Üzerinde Bir Araştırma. Atatürk Ünv. Yayınları No: 86.

Hseung Y, Jackson ML 1952. Mineral Composition of the Clay Fraction: III. Of Some Main Soil Groups of China Soil. Soil Science Society of America Journal, 16: 294297. USA.

Hussain MS, Uddin MJ, Ferdous S 2006. Clay Mineralogy and Morphology of some Wetland Soils from the Ganges Delta in Bangladesh. This presentation is part of 118: 1.0WB Wetlands: Science and Management-Poster.

Igwe CA, Akamigbo FOR, Mbagwu JSC 1999. Chemical and mineralogical properties of soils in southeastern Nigeria in relation to aggregate stability.Geoderma 92 (1999) 111-123.

İnce F 1984. Diyarbakır Yöresinde Yaygın Olan Bazı Büyük Toprak Gruplarının Kil Mineralleri ve Bunların Oluşum Nedenleri Üzerinde Bir Araştırma. AÜ. Ziraat Fakültesi Ankara.

Jackson ML 1962. Soil chemical analysis. Prentice-Hall Inc., 183.

Jackson ML 1969. Soil Chemical Analysis. Advanced Course. 2nd ed. Published by the Author, University of Wisconsin, Madison, 8955.

Kapur S, Gökçen SL, Yaman S 1990. Pedo-Sedimentological Aspects of Caliche Formations In The Misis Area Southern Adana Basin- Turkey, Terra-Nova Inta. Jour. of Earth Sciences.

Kapur S, Sayın M, Gülüt YK, Karaman C, Şahan S, Çavuşgil VS, Yılmaz K, Dinç U 1991. Harran Ovası Yaygın Toprak Serilerinin Mineralojik ve Mikromorfolojik Özellikleri. Proceedings 11.Congress of Soil Science Society of Turkey. Yay. No:6, s.85.

Korkmaz H 2005. Amik Gölü'nün Kurutulmasının Yöre İklimine Etkileri. MKÜ. BAP. Projesi, Proje No: 03 F 0701, Antakya.

Küçük A 2002. Amik Gölü'nün (Hatay) Kurutulması ile Oluşan Çevre Sorunları, İstanbul Üniversitesi, Sosyal Bilimler Enstitüsü, Basılmamış Yüksek Lisans Tezi, İstanbul.

Lavkor I 2006. Osmaniye İli Ve Çevresinde Bulunan Farklı Ana Materyaller Üzerinde Oluşan Topraklarda, Toprak Verimliliği-Bitki Besleme İlişkilerinin Belirlenmesi. Yüksek Lisans Tezi, Çukurova Üniversitesi Fen Bilimleri Enstitüsü. s. 78.

Mackereth FJH 1966. Some Chemical Observations on PostGlacial Lake Sediments. Philosophical Transactions of the Royal Society, 250, 165-213.

Sarı M, Altunbaş S, Yıldıran M 2000. Göller Yöresinde Kurutulan Kestel Göl Alanından Kazanılan Arazilerin Özelliklerinin Belirlenmesi Çevre Bakanlığı, Çevre Koruma Genel Müdürlüğü Araştırma Raporu, Ankara.

Sayın M 1983. Toprak Mineralojisi. Çukurova Üniversitesi Ziraat Fakültesi Ders Notu Yayınları No:78, Adana,168s.

Sayın M 1999. Toprak Mineralojisi. Ç.Ü. Ziraat Fakültesi Genel Yayın No:227. Ders Kitapları Yayın No: A-72. 
Seyrek A, Aydemir S, İnce F 2005. Harran Ovasında Tuzlulaşma Eğilimi Gösteren Toprakların Kil Mineralojisi. Atatürk Üniv. Ziraat Fak. Derg. 36 (2), 137 144, Issn : 1300-9036.

Stern RH, Ben-Hur M, Shainberg I 1991. Clay mineralogy effect on rain infiltration, seal formation and soil losses. Soil Sci. 150, 455-462.

Şenol H 2012. Göller Bölgesi Yaygın Büyük Toprak Gruplarının Fiziksel, Kimyasal Ve Mineralojik Özellikleri. Doktora Tezi Toprak Bilimi Ve Bitki Besleme Anabilim Dalı. Süleyman Demirel Üniversitesi Fen Bilimleri Enstitüsü-Isparta.

Şenol H, Özaytekin HH, Akgül M, Alaboz P 2014. Yarı Kurak Şartlarda Trakit/Trakiandezit Ana Materyal Üzerinde Oluşan Toprakların Ayrıșma Oranları ve Kil Mineralojisine Bakının Etkisi. Journal of Agricultural Sciences. 20, 288-301.

Şenol H, Akgül M 2013. Farklı Sıcaklık ve Nem Rejimleri ile Farklı Jeolojik Ana Materyal Üzerindeki Toprakların Olusumu ve Mineralojisi Süleyman Demirel Üniversitesi Ziraat Fakültesi Dergisi, 8(1), 41-52.

Thomas GW 1996. Soil pH and Acidity. P: 475-491. In D.L. Sparks (ed) Method of Soil Analysis: Chemical Methods. Part 3. SSSA, Madison, WI.

Tüzüner A 1990. Toprak ve Su Analiz Laboratuvarları El Kitabı. T.C. Tarım Orman ve Köy işleri Bakanlığı Köy Hizmetleri Genel Müdürlüğü. S.21-27.

Udeigwe TK 2001. Relatıng Suspended Solıds And Phosphorus In Surface Water Runoff From Agricultural Solls To Soll Salınity Measurements. A Thesis Submitted to the Graduate Faculty of the Louisiana State University and Agricultural and Mechanical College in partial fulfillment of the requirements for the degree of Master of Science in The Department of Agronomy and Environmental Management. B.S., University of Nigeria.

Yeşilsoy MŞ, Kapur S 1982. Mineralogy of Two Non-calcic Brown Soils Formed in the Sub humid Climate Region of Thrace Turkey. Çukurova Üni. Ziraat Fakültesi Yıllığı Yıl 13 Sayı 2.
Yılmaz K 1990. Harran Ovası Topraklarının Mineralojik Karakterizasyonları. Doktora Tezi. Ç. Ü. Fen Bilimleri Ens., Adana.

Yılmaz K 2001. Kahramanmaraş Bölgesinde Yer Alan Toprak Ordolarının Kil Mineralleri İçeriklerinin Kantitatif Tayini. KSÜ - Fen ve Mühendislik dergisi, Cilt 4, sayı 1.

Yılmaz K, Akça E 2000. Kahramanmaraş Ovası Topraklarının Kil Mineralojisi Ve Yavaş Yararlı Potasyum İçerikleri, KSÜ Fen ve Mühendislik Dergisi 2000, Cilt 3, say1 1.

Yılmaz K, Çelik İ, Kapur S, Ryan J 2005.Clay Minerals, $\mathrm{Ca} / \mathrm{Mg}$ Ratio and $\mathrm{Fe}-\mathrm{Al}-\mathrm{Oxides}$ in Relation to Structural Stability, Hydraulic Conductivity and Soil Erosion in Southeastern Turkey. Turk J Agric For 29 (2005) 29-37 (C) TÜBiTAK.

Yılmaz K, Gündoğan R, Demirkıran AR 1998. Pedogenesis and Classification of Soils in Kahramanmaraş Province, Turkey. International Symposium on Desertification ISD, Proceedings p: 517-524. Konya-Turkiye.

Yılmaz K, Sayın M 1998. Çukurova Bölgesi Yaygın Toprak Serilerinde Çarpım Faktörü Yöntemi ile Kantitatif Kil Analizi, KSÜ Fen ve Mühendislik Dergisi, Cilt: 2, Sayı: 1. 36-46.

Yılmaz K 1999. Harran Ovası Topraklarında Smektit ve Paligorskit Oluşumu, Turkish Journal of Agriculture and Forestry, 23 Ek Sayı: 31 635-642

Yurdakul İ 2009. Ağır Bünyeli Toprakta Bazı Toprak Bileşenlerinin Fosfor Adsorpsiyon Kapasitesine Etkilerinin Langmuir İzotermleri İle Araştırılması. Doktora Tezi. Ankara Üniversitesi Fen Bilimleri Enstitüsü. Toprak Anabilim Dalı.

Zor M, Şengün MT 2002. "Amik Ovasının Hidroğrafik Özelliklerinde Meydana Gelen Değișmeler ve Bunun Sonucunda Ortaya Çıkan Sorunlar", Su Havzalarında Toprak ve Su Kaynaklarının Korunması Geliștirilmesi ve Yönetimi Sempozyumu: 338-343, 18-20 Ekim 2002. Antakya/Hatay 